\title{
A case of Ogilvie's syndrome associated with electrolyte imbalance in a healthy individual
}

\author{
Robin George Manappallil', Chinganthara Cleetus Suresh², Dilshad Kadengil ${ }^{3}$, \\ Prasad Thomas ${ }^{4}$, Jishnu Jayaraj ${ }^{5}$ \\ ${ }^{1}$ Consultant-Physician, ${ }^{5}$ Medicine Resident, Department of Internal Medicine, Baby Memorial Hospital, Calicut, Kerala, \\ ${ }^{2}$ Senior Consultant and Head of Department, ${ }^{3}$ Consultant-Surgeon, ${ }^{4}$ Surgery Resident, Department of General Surgery, \\ Baby Memorial Hospital, Calicut, Kerala, India
}

Ogilvie's syndrome or acute colonic pseudo-obstruction is a rare and acquired disorder characterized by significant dilatation of the colon. The condition is mainly seen in hospitalized patients with medical or surgical problems. We report the case of a middle aged healthy lady who presented with Ogilvie's syndrome and associated electrolyte imbalance in the form of hypokalemia and hypomagnesemia. Ogilvie's syndrome itself is a rare condition, and to the best of our knowledge has not been reported among healthy individuals yet.

Key words: Ogilvie's syndrome, Pseudo obstruction colon, Hypokalemia, Hypomagnesemia

\section{Access this article online}

Website:

http://nepjol.info/index.php/AJMS

DOI: 10.3126/ajms.v8i1.15757

E-ISSN: 2091-0576

P-ISSN: 2467-9100

\section{INTRODUCTION}

Acute colonic pseudo-obstruction, otherwise known as Ogilvie's syndrome (OS), is a rare and acquired disorder seen in debilitated medical or surgical patients. It mainly involves the right colon and is characterized by acute massive dilatation of the colon in the absence of any mechanical cause. Electrolyte imbalances like hypokalemia, hyponatremia, hypomagnesemia and hypocalcemia have been associated with OS. We report the case of a middle aged lady who presented with 2 days history of constipation and abdominal distension; and was diagnosed to have OS with electrolyte imbalance. The occurrence of OS in a healthy individual is a rare scenario.

\section{CASE REPORT}

A 48 year old lady, unmarried and illiterate, hailing from a rural area, was brought to the Emergency Department with 2 days history of constipation and progressive abdominal distension, associated with mild abdominal pain. She had 4 to 5 episodes of vomiting and was nauseous. She had history for 3 episodes of watery diarrhoea 1 day prior to constipation. She also noticed mild weakness of both lower limbs, as she was having difficulty in walking without support. The weakness was not associated with any muscle tenderness or spasms. There was no upper limb involvement. There were no history similar episodes in the past. She did not have any comorbid conditions like hypertension, diabetes or thyroid disorders.

On examination, she was conscious, oriented, and moderately built. She was afebrile and had a heart rate of 80 beats/minute, blood pressure of 130/90 $\mathrm{mmHg}$, respiratory rate of $22 /$ minute with saturation $94 \%$ (room air). Her abdomen was distended with mild diffuse tenderness on palpation. There were no skin discolorations. There was no guarding or rigidity; and no organomegaly. Tympanitic note was heard on abdominal percussion. Bowel sounds were absent on auscultation. Neurological examination revealed a power of $4 / 5$ at both hip and knee joints and $5 / 5$ at the ankles. Her lower limb deep tendon reflexes were diminished. There were no fasciculations and plantars were bilaterally flexors. Her upper limb power and reflexes were not affected. There was no cranial nerve or 
sensory involvement and no spinal abnormalities. Other systemic examinations were normal.

Her plain abdominal film showed dilatation of the colon (Figure 1) and contrast enhanced computerized tomography of the abdomen revealed a grossly distended sigmoid colon with normal proximal colon and normal distal transition to rectum suggestive of colonic pseudoobstruction (Figure 2). Her blood investigations showed hyponatremia of $130 \mathrm{mEq} / \mathrm{L}$ (136-146), hypokalemia of $2.8 \mathrm{mEq} / \mathrm{L}(3.5-5)$ and hypomagnesimia of $1.27 \mathrm{mg} \%$ $(1.5-2.3)$. Her arterial blood gas showed metabolic alkalosis. Her urine potassium was $15 \mathrm{mmol} / \mathrm{day}$, which was suggestive of an extra-renal loss; and urine microscopy was normal. Her complete blood count, renal and liver functions were normal. Serum calcium was $8.5 \mathrm{mg} / \mathrm{dL}(8.7-10.2)$ and thyroid profile was normal. HbA1c was also within normal range. ANA and Anti dsDNA were negative. ECG and chest X-ray were normal.

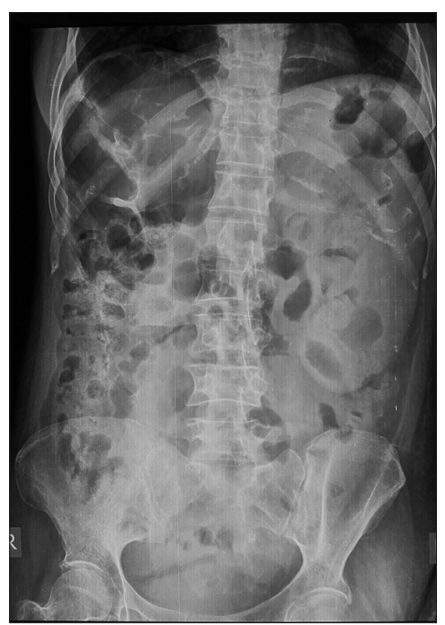

Figure 1: Colonic dilatation

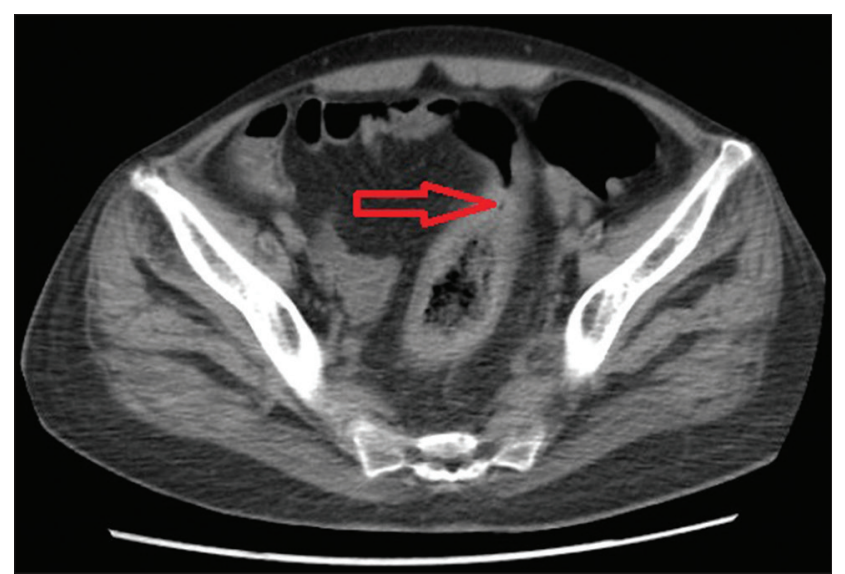

Figure 2: Colonic pseudo-obstruction
Based on the history, examination and investigative findings, the diagnosis of OS with associated electrolyte imbalance was considered. She was kept nil per oral and Ryles tube was placed. Intravenous magnesium sulphate, intravenous $10 \%$ calcium gluconate and normal saline with $40 \mathrm{mEq}$ potassium chloride were given. Her electrolytes were corrected within 24 hours of admission, following which patient passed stools and was symptomatically better in terms of abdominal complaints and lower limb weakness. She was discharged after 96 hours of admission with normal electrolyte values.

\section{DISCUSSION}

Acute colonic pseudo-obstruction, otherwise known as Ogilvie's syndrome (OS) is a rare and acquired disorder, characterized by acute dilatation of the colon without any mechanical obstruction. It was first described by Sir Heneage Ogilvie in 1948. It is more often seen in elderly hospitalized patients with medical problems like cardiovascular, neurological and renal ailments or in post-surgical and post-traumatic conditions. Other associated conditions include electrolyte imbalance, alcohol abuse, sepsis, neoplasia and drugs like antiparkinsonian agents, antidepressants and narcotics. A disruption in the autonomic nervous system is considered as the main cause in the pathogenesis of OS. Abdominal distension associated with nausea, vomiting and abdominal pain are some of the main features of OS. These symptoms may develop gradually over a few days or even acutely within 24 hours. Some patients may present with low grade fever. Electrolyte imbalances in the form of hypokalemia, hypomagnesemia, hyponatremia and hypocalcemia have been noted. Intestinal perforation is the main complication. Colonic decompression with correction of electrolyte imbalances and etiology is the goal of treatment. Medical decompression with neostigmine, endoscopic decompression, percutaneous cecostomy and surgical decompression (cecostomy, colostomy or resection) are some of the modalities of treatment. ${ }^{1}$

Only a handful of cases of OS have been reported. A case of caecal perforation in a patient with OS following caesarean section was reported by Saha et al. ${ }^{2}$ Another two cases of post caesarean OS were reported by Fatnassi et $a .^{3}$ OS with intestinal perforation was noticed by Jani in an elderly lady. ${ }^{4}$ According to a case series by Tenofsky et al, patients undergoing orthopedic and spinal surgeries were at higher risk of developing OS as a postoperative complication. ${ }^{5}$ In another case series by Mehta et al, OS was diagnosed in a patients admitted in critical care unit. But these patients had underlying medical conditions like 
diabetes, hypertension and stroke. ${ }^{6}$ Hypokalemia associated with OS was observed by Sunnoqrot et al in a patient with multiple comorbidities. ${ }^{7}$ In contrast to the above cases, our patient was a healthy individual with no comorbid condition or any medical or surgical ailments.

\section{CONCLUSION}

OS is a rare condition seen among patients with cardiac, renal or neurological ailments or among those taking certain medications. It may also occur as a postoperative complication. Electrolyte imbalance has been associated with OS. Our patient presented with acute onset intestinal obstruction and was diagnosed to have OS with electrolyte imbalance. She did not have any ailments or comorbidities and did not undergo any surgical procedures. To the best of our knowledge, such a scenario of OS presenting in a healthy individual has not been reported yet.

\section{REFERENCES}

1. Orenstein AEF. Ileus and Pseudo-obstruction. In: Feldman M, Friedman LS, Brandt LJ eds. Sleisenger and Fordtran's Gastrointestinal and Liver Disease: Pathophysiology/ Diagnosis/ Management. 9th ed. New Delhi: Elsevier, 2010, pp 2128-2130.

2. Arin K, Saha AK, Newman E, Giles M and Horgan K. Ogilvie's syndrome with caecal perforation after Caesarean section: a case report. Journal of Medical Case Reports 2009; 3:6177.

3. Fatnassi R, Mkhinini I, Abdelkefi MS, Torki E, Hammami S and Barhoumi H. Ogilvie's Syndrome: A Caesarean Section Complication (A Two Cases Report and Review of the Literature). EC Gynaecology 2015; 1(1): 35-40.

4. Jani PG. Acute colonic pseudo obstruction (Ogilvie's syndrome): case report. East Afr Med J 2005; 82(6):325-328.

5. Tenofsky PL, Beamer R and Smith R. Ogilvie Syndrome as a Postoperative Complication. Arch Surg 2000;135(6):682-687.

6. Mehta R, Suvarna D, Sadasivan S, Rajesh G and John A. Acute colonic pseudo-obstruction (Ogilvie's syndrome) in critical care unit. Indian J Crit Care Med 2004; 8(1): 43-45.

7. Sunnogrot $N$ and Reilly RF. Hypokalemia Associated with Colonic Pseudo-Obstruction (Ogilvie's Syndrome). Case Rep Nephrol Dial 2015; 5:118-123.

Authors Contribution:

RGM - Concept and design of case report, reviewed the literature, manuscript preparation, critical revision of manuscript and treating physician; CCS - Critical revision of manuscript and treating surgeon; DK - Reviewed the literature and treating surgeon; PT - Surgery resident incharge; JJ - Medicine resident incharge.

Source of Support: Nil, Conflict of Interest: None declared. 